Asian J. Med. Biol. Res. 2020, 6 (3), 383-399; doi: 10.3329/ajmbr.v6i3.49786

\author{
Asian Journal of \\ Medical and Biological Research \\ ISSN 2411-4472 (Print) 2412-5571 (Online) \\ www.ebupress.com/journal/ajmbr
}

\title{
Article \\ Isolation, identification and molecular detection of selected probiotic bacteria from broiler chickens and their related environment
}

\author{
Tuhin-Al-Ferdous, Md. Shahidur Rahman Khan and S. M. Lutful Kabir* \\ Department of Microbiology and Hygiene, Faculty of Veterinary Science, Bangladesh Agricultural University, \\ Mymensingh-220, Bangladesh
}

*Corresponding author: Professor Dr. S. M. Lutful Kabir, Department of Microbiology and Hygiene, Bangladesh Agricultural University, Mymensingh-2202, Bangladesh. Phone: +8801754987218; E-mail: lkabir79@bau.edu.bd

Received: 03 August 2020/Accepted: 28 September 2020/ Published: 30 September 2020

\begin{abstract}
This study was aimed to isolate and identify the potential probiotic bacteria from broiler chickens and their related environment of the two districts in Bangladesh by using cultural and biochemical techniques and detection of the selected isolated probiotic potential bacterial species by using polymerase chain reaction (PCR). In this context five probiotic bacteria species of five bacteria genera were screened out from 750 samples in where there were 186 Lactobacillus genus isolates, 102 Bacillus genus isolates, 112 Streptococcus genus isolates, 220 Enterococcus genus isolates and 33 Bifidobacterium genus isolates on the basis of biochemical properties like $10 \%$ solution of total 22 different sugars. Other biochemical tests like MR-VP, Oxidase, Catalase, Citrate utilization, MIU and Indole test were major. Genus was detected through specific genus target gene and 16S r DNA based PCR. Selected probiotic bacteria species were detected through species specific target gene PCR. We confirmed 23 Lactobacillus acidophilus species isolates, 14 Bacillus subtilis isolates, 19 Streptococcus thermophilus isolates, 31 Enterococcus faecium isolates and 09 Bifidobacterium bifidum isolates at species level with $d d l$ gene, apr-E gene, $16 S$-23S ITS gene, BIBI gene, Stp-TH gene primers. The novelty of this study is at first time in Bangladesh, we isolated and identified five selected potential probiotic species from the gastro-intestinal tract of broiler chickens and their related environmental sources by not only using traditional cultural, biochemical techniques but also genus and species specific target gene based PCR.
\end{abstract}

Keywords: Lactobacillus; Bacillus; Streptococcus; Bifidobacterium; Enterococcus; biochemical; PCR; probiotic; broiler chickens

\section{Introduction}

The widespread use of antibiotics all around the world not only as therapeutic and prophylactic agents but also as growth promoters in poultry industry has led to a wide increase in antibiotic resistance and the emergence of untreatable multidrug resistant strains of bacteria and other microbes (Kabir, 2009). However, the growing concern of the international community on the use of antibiotics in animal production has led to an increase of the so called antibiotic free production (Cristiano et al., 2019). But what should be the alternative for this and what was the background of this study? European Union banned the utilization of antibiotics as growth promoters in all of edible animal production in 2006. Now for what we isolated and identified common probiotic bacterial species belongs to Lactobacillus, Bacillus, Bifidobacterium, Streptococcus, Enterococcus genus. Probiotic is derived from Greek word "Probios" and it means for life. According to FAO and WHO the term "Probiotic" refers to "live microorganisms which, when administered in adequate amounts, confer a health benefit on the host (FAO, 2002; WHO, 2002). Another way, it is defined as a "live microbial product" which beneficially affects the host animal by improving its intestinal microbial balance (Fuller, 1989). Probiotic species belonging to Lactobacillus, Streptococcus, Bacillus, Bifidobacterium, Enterococcus, Aspergillus, 
Candida, and Saccharomyces have a beneficial effect on broiler performance, pathogen inhibition and immunomodulation (Kabir, 2009). The ultimate target of this research was to develop a cost effective and potent probiotic for the poultry industry by isolation, identification and molecular detection of selected potential bacterial species from the gastro-intestinal tract of locally rearing broiler chickens and their related environmental sources like litter, feeder, water drinkers with cultural, biochemical and molecular techniques. Lactobacillus, Bacillus, Bifidobacterium, Streptococcus, Enterococcus genus were chosen as probiotic for the poultry industry because they are beneficial commensals of chickens and have proven as potential probiotic through probiotic ability tests. Moreover, these probiotic bacteria strongly aggregate with other pathogenic bacteria, compete for adhesion to epithelial receptors of host, modify the structure and function of intestinal epithelium of host, modify total microbiota of host intestine, take apart for competition for nutrients of host body and produce some specific substances like organic acids, bacteriocine, dipicolinic acids (Peera and James, 2013). In Bangladesh, there are many foreign commercial probiotics are available in market and their indiscriminate use without local reliable experimental support can't be justified. These products are also expensive for the poultry rearer as well. That's why we attempted to isolate, identify and molecular detection of all above mentioned probiotic bacteria. Yet, the proper chain handle of these live bacteria containing imported product preparation hasn't maintained neither at seller nor farmer level. Indeed, it's a great problem here. Therefore, this unique research was undertaken for isolation, identification and detection of selected multi bacterial species from totally indigenous sources at the first time in Bangladesh.

\section{Materials and Methods}

\subsection{Study area}

A total of 750 samples were collected from 10 farms of two districts in Bangladesh. The lab work and other accessories work were performed mainly in Department of Microbiology and Hygiene, Department of Physiology, Central Laboratory of Bangladesh Agricultural University, Bangladesh.

\subsection{Collection of samples}

Total samples were collected from gastro-intestinal tracts of locally rearing broiler chickens like 300 caecum, 300 cloacal swab samples and their related environment which includes the samples from 50 water drinkers, 50 feeder and 50 floor litter samples. After collection the samples were preserved at $0.1 \%$ peptone water and cool ice box until reached to laboratory.

\subsection{Isolation and morphological characteristics of probiotic bacteria}

The total samples were processed and somewhere it was needed to grind with mortar and pestle at the very beginning of processing. The sample aliquots were inoculated in Nutrient broth, MRS broth and BSM broth then incubated at $37^{\circ} \mathrm{C}$ for $24 \mathrm{hrs}$ to $36 \mathrm{hrs}$. After then, we have gone for primary culture in specific agar media and then secondary culture for isolation of selected bacteria in selective enrich agar media. Sub cultured into specific selective media until obtaining single pure colonies of five bacterial species of five genera. Tentative pure colonies were isolated through morphological characterization, Gram's staining and culture characteristics. In where, another technique was biochemical characterization by fermentation of $10 \%$ solution of different 22 sugars. Other biochemical properties were characterized by the MR-VP Test, Oxidase, Catalase Test, Indole Test, Citrate utilization Test, MIU (Motility) Test. Somewhere we used zigzag streaking method or straight streaking method and finally we found pure colonies of Lactobacillus on MRS Agar ${ }^{\mathrm{TM}}$ which were distinct white or whitish yellow and Gram staining properties included positive, rod or ovoid shaped with tapering end (Kamrun et al., 2016). Gram staining positive, rod with square ends, large rod shaped organisms, arranged in chain are characteristics of Bacillus subtilis (Jones et al., 1987). The surface was finely granular and slightly sticky, large, sporulated, rod-shaped bacteria (Merchant and Packer, 1967). Maximum of all these species are sub terminal, endospore formed, motile and on Bacillus Differentiation agar (Himedia, India) we found large ellipsoidal, slightly sticky, blue pure colonies. Members of the genus Enterococcus include gram positive, facultatively anaerobic cocci that are ovoid in form and can occur in singlet, pairs or short chains (Facklam, 2002). On Enterococcus Faecium agar base (Himedia, India) we found luxuriant green colored pure colonies. Bifidobacterium bifidum colonies were convex, creamy, white or grayish, glossy, smooth, neat-edgeed, soft, sticky on BSM agar media and TOS-Propionate Agar media. The colonies were dew drop like small flat distinct brown colored on MRS agar media. In Nutrient Agar medium, normally produced small grayish round colonies. In Streptococcus Thermophilus Isolation Agar Medium ${ }^{\mathrm{TM}}$, the colonies were round, flat, large grayish sticky. 
For cultural morphological characterization, we used MRS agar (Himedia, India), Hicrome Bacillus agar (Himedia, India), Bacillus Differentiation agar (Himedia, India), Streptococcus Thermophilus isolation agar (Himedia, India), Enterococcus Faecium agar base (Himedia, India), Enterococcus Differential Agar Base (Himedia, India), TOS-Propionate Agar acc. (Sigma -Aldrich, India).

\subsection{Identification of probiotic bacteria by using biochemical tests}

Biochemical characterization was performed by fermentation of $10 \%$ solution of different 22 sugars like DGalactose, D-Fructose, L-Arabinose, Maltose, L-Rhamnose, D-Mannitol, D-Sorbitol, Methyl-alpha-D-Glucopyranoside, Amygdaline, D-Ribose, Melebiose, Lactose, Raffinose, Sucrose, Melizitose, Xylose, Trehalose, Arginine, Salicine, NAG amine, Glucose, Dextrose, L-Rhamnose. Other biochemical properties were characterized by the MR-VP Test, Oxidase, Catalase Test, Indole Test, Citrate utilization Test, MIU (Motility) Test. Finally, we confirmed about five specific probiotic bacterial species of five genera through molecular detection (PCR).

\subsection{Molecular detection of probiotic bacteria}

Finally, we confirmed about five specific probiotic bacterial species of five genera through molecular detection (PCR). Genus was detected through specific genus target gene and 16S r DNA based PCR. Selected probiotic bacteria species were detected through species specific target gene PCR. We confirmed Lactobacillus acidophilus species isolates, Bacillus subtilis isolates, Streptococcus thermophilus isolates, Enterococcus faecium isolates and Bifidobacterium bifidum isolates at species level with $d d l$ gene, apr-E gene, 16S-23S ITS gene, BIBI gene, Stp-TH gene primers accordingly.

\subsubsection{DNA extraction}

DNA was extracted from pure colonies of five selected probiotic bacteria samples as follows / regards: harvested up to $2 \times 10^{9}$ bacterial cells in a $1.5 \mathrm{ml}$ micro centrifuge tube centrifugation for 10 minutes at 5000xg. Then discarded the supernatant and resuspended the pellets in $180 \mu \mathrm{l}$ of Gram positive bacteria lysis buffer $(20$ $\mathrm{mM}$ Tris- $\mathrm{HCl}, \mathrm{Ph} 8.0,02 \mathrm{mM}$ EDTA, $1.2 \%$ Ttiton x 100, add lysozyme to $20 \mathrm{mg} / \mathrm{ml}$ immediately before use). Incubated for 30 minutes for $37^{\circ} \mathrm{C}$, then we added $200 \mu \mathrm{l}$ of lysed sample solution and then added $20 \mu \mathrm{l}$ proteinase-k. Mixed properly by vortexing and pipetting to obtain a uniform suspension. Incubated the sample at $56^{\circ} \mathrm{C}$ while shaking water bath until the cells were completely lysed (30 minutes), then added $20 \mu \mathrm{l}$ of RNase-A solution (Thermo-Fisher Scientific, Lithonia), mixed by vortexing and kept the mixture for 10 minutes at room temperature. Then $400 \mu \mathrm{l}$ of $50 \%$ Ethanol was added and properly mixed by pipetting. Transferred the prepared lysate solution to a Gene JET Genomic DNA purification column and inserted in a collection tube and centrifuged the column for 01 minute at 6000xg. Discarded the collection tube containing the flow-through solution. The Gene JET Genomic DNA purification column was placed into a new $02 \mathrm{ml}$ collection tube. $500 \mu \mathrm{l}$ of wash Buffer-I with ethanol was added. Then centrifuged at 8000xg for 01 minute. Discarded the flow-through and placed the purification column back into collection tube. $500 \mu \mathrm{l}$ of wash Buffer-IIwith ethanol was added into the Gene JET Genomic DNA purification column. Centrifuged at $\geq 12000 x g$ speed for 03 minutes, respined the column for 01 minute at maximum speed. Discarded the collection tube containing the flow-through solution and the Gene JET Genomic DNA purification column was transferred to a sterile $1.5 \mathrm{ml}$ eppendorf tube. Finally, $200 \mu \mathrm{l}$ of Elution Buffer was added to the centre of Gen JET Genomic DNA purification column membrane to elute genomic DNA. Incubated for 02 minutes at room temperature and centrifuged at $8000 \mathrm{xg}$ for 01 minute. Discarded the purification column tube, then used the purified DNA immediately in downstream applications and remaining was stored at $-20^{\circ} \mathrm{C}$.

\subsubsection{PCR analysis}

\subsubsection{Lactobacillus and Lactobacillus acidophilus PCR based detection}

Identification of the Lactobacillus acidophilus isolates with genus specific primers designed by Magne et al., 2006. Target 472 bp 16S rRNA gene fragment from all suspected Lactobacillus isolates were amplified by PCR using the primers 16S rRNA with FW: 5'-CTC CTA CGG GAG GCA GCA GT-3' and REV: 5'GGACTACCAGGGTATCTA A-3'; inwhere, PCR condition for each suspected Lactobacillus genus isolate was as follows: $25 \mu$ of PCR mixture contained with $12.5 \mu$ master mix (GoTaq ${ }^{\circledR}$ G2 Green Master Mix,2X: GoTaq ${ }^{\circledR} \mathrm{G} 2$ DNA Polymerase was supplied in GoTaq ${ }^{\circledR} \mathrm{G} 2$ reaction buffer with Ph 8.5, $400 \mu \mathrm{M}$ d-ATP, $400 \mu \mathrm{M}$ d-GTP, $400 \mu \mathrm{M}$ d-CTP, $400 \mu \mathrm{M}$ d-TTP and $3 \mathrm{mM} \mathrm{MgCl}$, Madison, WI USA), FW:1 $\mu \mathrm{l}(10 \mathrm{pmol} / \mu \mathrm{l})$, REV: 1 
$\mu \mathrm{l}(10 \mathrm{pmol} / \mu \mathrm{l})$, Nuclease Free Water: $5.5 \mu \mathrm{l}$, DNA Template: $5 \mu \mathrm{l}$, initial denature temperature at $94^{\circ} \mathrm{C}$ for 5 minutes, 30 cycles of $94^{\circ} \mathrm{C}$ for 60 seconds at annealing at $55^{\circ} \mathrm{C}$ for 60 seconds, extension at $72^{\circ} \mathrm{C}$ for 90 seconds $\&$ final $72^{\circ} \mathrm{C}$ for 10 minutes. Final PCR product was loaded in $1.5 \%$ agarose gels with Bench Top 100 bp DNA Ladder (consists of 11 double-stranded DNA fragments with sizes from 100-1500 bp, Promega, Madison, WI USA) and ran at 80 Volt for 25 minutes. Finally, identification of Lactobacillus acidophilus isolates with species specific primers according to Song et al., 2000. A 210 bp target 16S-23S rDNA ISR (Intergenic Spacer Region) Laci-I: FW:5-TGCAAAGTGGTAGCGTAAGC-3, 23-10C: REV:5-CCTTTCCC TCACGGTACTG-3; in where, $12.5 \mu \mathrm{l}$ master mix, FW: $1 \mu \mathrm{l}(10 \mathrm{pmol} / \mu \mathrm{l})$, REV: $1 \mu \mathrm{l}(10 \mathrm{pmol} / \mu \mathrm{l})$, Nuclease Free Water: $5.5 \mu \mathrm{l}$, DNA Template: $5 \mu \mathrm{l}$ and total volume of PCR mixture was $25 \mu$, initial denaturation temperature was $95^{\circ} \mathrm{C}$ for 03 minutes, annealing at $68^{\circ} \mathrm{C}\left(60\right.$ seconds), $72^{\circ} \mathrm{C}$ for 1 minute, concluded with each reaction a 10 minutes final extension at $72^{\circ} \mathrm{C}$.

\subsubsection{Bacillus and Bacillus subtilis PCR based detection}

Detection of Bacillus isolates with genus specific primers have described by Kim et al., 2010. In where, target PCR band product size was $1.5 \mathrm{~kb}(1500 \mathrm{~kb}) 16 \mathrm{~S}$ rRNA gene from all suspected Bacillus isolates were amplified by PCR using forward and reverse primers sequence with 27F: 5'-AGAGTTTGATCCTGGCTCAG-3', 1492R: 5'-GGCTACCTTGTTACGACTT-3'. Each PCR product was amplified according to the conditions as follows: initial denaturation temperature was 30 cycles, at $95^{\circ} \mathrm{C}$ for 1 minute, annealing at $45^{\circ} \mathrm{C}$ for 1 minute, extension at $72^{\circ} \mathrm{C}$ for $90 \mathrm{~s}$ and 10 minutes final incubation at $72^{\circ} \mathrm{C}$. Isolates of Bacillus subtilis detection at species level was carried out according to Alireza Sadeghi et al., 2012. Target 744 bp apr-E genes with FW and REV primers sequence with apr-E: FW: TTTACGATGGCGTTCAGCAAC, apr-E: REV: GGAAGTGCCTTCA TTTCCGGCT. Total volume of PCR product was $25 \mu \mathrm{l}$; initial denaturation temperature was $94^{\circ} \mathrm{C}$ for 4 minutes followed by 35 cycles, annealing at $57^{\circ} \mathrm{C}$ for 40 seconds, extension $72^{\circ} \mathrm{C}$ for 1 minutes, concluded with Each reaction a 05 -minutes final extension at $72^{\circ} \mathrm{C}$, primers concentration of $2 \mu \mathrm{L}$ of each primer with $0.5 \mathrm{mmol}$ L-1. Final PCR product was loaded in 1.5\% agarose gels with BenchTop 100 bp DNA Ladder (consists of 11 double-stranded DNA fragments with sizes from 100-1500 bp, Promega, Madison, WI USA) and ran at 80 Volt for 25 minutes.

\subsubsection{Bifidobacterium and Bifidobacterium bifidum PCR based detection}

Detection of Bifidobacterium isolates with genus specific primers have described by Langendijk et al. (1995). In where, target PCR band product size was 510 bp 16S rRNA gene from all suspected Bifidobacterium isolates were amplified by PCR using forward and reverse primers sequence with Bif164-f: 5'GGGTGGTAATGCCGGATG-3', Bif662-r: 5'-CCACCGTTACACC GGGAA-3'. Each PCR product was amplified according to the conditions as follows: initial denaturation temperature was 1 st cycle of $94^{\circ} \mathrm{C}$ for 3 minutes and 35 cycles of $94^{\circ} \mathrm{C}$ for 30 seconds, annealing at $60^{\circ} \mathrm{C}$ for 1 minutes, extension at $68^{\circ} \mathrm{C}$ for 2 minutes and $68^{\circ} \mathrm{C}$ for 7 minutes. Isolates of Bifidobacterium bifidum detection at species level was carried out according to Matsuki et al., 1998. Target 278 bp BIBI gene with FW and REV primers sequence with FW: 5CCACATGATCGCATGTGATTG-3, REV: 5-CCG AAG GCT TGC TCCCAAA-3. Total volume of PCR product was $25 \mu \mathrm{l}$; initial denaturation temperature was one cycle of $94^{\circ} \mathrm{C}$ for 5 minutes followed by 35 cycles of $94^{\circ} \mathrm{C}$ for 20 seconds, annealing at $55^{\circ} \mathrm{C}$ for 20 seconds, extension at $72^{\circ} \mathrm{C}$ for 30 seconds, concluded with final reaction cycle at a $72^{\circ} \mathrm{C}$ for 5 minutes, primers concentration of $25 \mu \mathrm{M}$ of each primer. Final PCR product was loaded in 2\% agarose gels with BenchTop 100 bp DNA Ladder (consists of 11 double-stranded DNA fragments with sizes from 100-1500 bp, Promega, Madison, WI USA) and ran at 80 Volt for 25 minutes.

\subsubsection{Streptococcus and Streptococcus thermophilus PCR based detection}

Molecular detection of Streptococcus genus using PCR, primers pair specific to 16S rDNA of Streptococcus was performed according to Sato et al., 2003. The sequence of 16S rDNA was amplified by using total PCR mixture of $25 \mathrm{ul}$ volume for each suspected isolates. The target amplicon size was $1505 \mathrm{bp}$ with $8 \mathrm{UA}-\mathrm{FW}$ and 1492-REV primers sequence of 8UA-FW: 5'-AGAGTTTGATCMTGGCTCAG-3', 1492-RW: 5'TACGGYTACCTGTTACGACTT-3', 15 minutes at $95^{\circ} \mathrm{C}$ for initial heat activation and denaturation with 35 cycles, 1 minute at $55^{\circ} \mathrm{C}$ for annealing, extension at 1.5 minutes at $72^{\circ} \mathrm{C} \&$ a final elongation of $72^{\circ} \mathrm{C}$ for 10 minutes and primer concen. $1 \mu \mathrm{l}$ of each primer $(5 \mu \mathrm{M})$.

(*Reaction conditions for $S$. themophilus PCR were $0.2 \mu \mathrm{g} / \mu \mathrm{l}$ DNA, $10 \mathrm{~m} M$ Tris- $\mathrm{HCl}$ (pH 8.3), $50 \mathrm{~m} M \mathrm{KCl}, 1.5$ $\mathrm{m} M \mathrm{MgCl}$, a $200 \mu M$ concentration of each dATP, dCTP, dGTP, and dTTP, $1 \mu M$ Stp Th-F, $1 \mu M$ Stp Th-R, 2.5 
units Applied Biosystems Ampli Taq DNA polymerase. Amplification conditions were $95^{\circ} \mathrm{C}$ for 3 minutes; 35 cycles. Reaction conditions varied regarding $\mathrm{MgCl} 2$ concentration $(2.5 \mathrm{mM})$ as well as Taq polymerase $(2.5$ units Applied Biosystems Ampli Taq DNA polymerase described by Jeanne et al. (2005). For all isolates of suspected S. thermophilus, 968 bp of Stp-TH-FW and Stp-TH-REV fragment was detected confirming the species to the genus Streptococcus. Streptococcus thermophilus species were isolated from the all samples according to Lick et al., 2001. Applied Biosystems AmpliTaq DNA polymerase with Stp-TH-FW: 5-CAC TAT GCT CAG AAT ACA-3, Stp-TH-REV: 5-CGA ACA GCA TTG ATG TTA-3, in where, PCR condition for each suspected Streptococcus thermophilus isolate was as follows: $25 \mu 1$ of PCR mixture contained with $12.5 \mu 1$ master mix, Forward primer : $1 \mu \mathrm{M}$, Reverse primer: $1 \mu \mathrm{M}$, Nuclease Free Water: $5.5 \mu \mathrm{l}$, DNA Template: $5 \mu$, initial (denaturation at $94^{\circ} \mathrm{C}$ for 20 seconds, annealing at $58^{\circ} \mathrm{C}$ for 30 seconds, extension at $68^{\circ} \mathrm{C}$ for 30 seconds; $68^{\circ} \mathrm{C}$ for 5 minutes of final extension. Final PCR product was loaded in 1.5\% agarose gels with BenchTop 100 bp DNA Ladder (consists of 11 double-stranded DNA fragments with sizes from 100-1500 bp, Promega, Madison, WI USA) and ran at 80 Volt for 25 minutes.

\subsubsection{Enterococcus and Enterococcus faecium PCR based detection}

A systematic molecular approach, followed by the targeting genus and species specific gene based PCR. The amplicon size of genus of Enterococcus was 112 bp with Ent-1 FW, Ent-2 Rev primers targeting the 16S-23S ITS rDNA according to Ke et al., 1999. In where, sequence of Ent-1: FW: 5TACTGACAAACCATTCATGATG-3, Ent-2: Rev: 5-AACTT CGTCA CCAACGCGAAC-3, in where, PCR condition for each suspected Enterococcus isolate was as follows: $25 \mu \mathrm{l}$ of PCR mixture contained with $12.5 \mu \mathrm{l}$ master mix $\left(\mathrm{GoTaq}^{\circledR} \mathrm{G} 2\right.$ Green Master Mix, 2X: GoTaq ${ }^{\circledR} \mathrm{G} 2$ DNA Polymerase was supplied in GoTaq ${ }^{\circledR} \mathrm{G} 2$ reaction buffer with Ph 8.5, $400 \mu \mathrm{M}$ d-ATP, $400 \mu \mathrm{M}$ d-GTP, $400 \mu \mathrm{M}$ d-CTP, $400 \mu \mathrm{M}$ d-TTP and $3 \mathrm{mM} \mathrm{MgCl}_{2}$, Madison, WI, USA), Forward primer: $0.2 \mu \mathrm{M} / \mu \mathrm{L}$, Reverse primer: $0.2 \mu \mathrm{M} / \mu \mathrm{L}$, Nuclease Free Water: $5.5 \mu$, DNA Template: $5 \mu \mathrm{l}$, initial denature temperature at 3 minutes at $95^{\circ} \mathrm{C}$ and then followed by 35 cycles of 30 seconds, at $95^{\circ} \mathrm{C}$, annealing at 30 seconds, at $55^{\circ} \mathrm{C}$ \& extension at 1 minutes at $72^{\circ} \mathrm{C}$, with a 7 minutes final $72^{\circ} \mathrm{C}$. Molecular detection of Enterococcus faecium from suspected isolates were performed according to Dukta-Malen et al.,1995, targeting a 550bp $d d l$ gene based species specific PCR. In where, PCR using forward and reverse primers sequence with $d d l$ FW: 5'-TAGAGACATTGAATATGCC-3', $d d l$ Rev: 5'CTAACATCGTGTAAGCT-3'. Each PCR product was amplified according to the conditions as follows: initial denaturation temperature was $94{ }^{\circ} \mathrm{C}$ for 2 minutes for the 1 st cycle and 30 cycles of $94{ }^{\circ} \mathrm{C}$ for 01 minute, annealing at $54^{\circ} \mathrm{C}$ for 01 minute, extension at $72^{\circ} \mathrm{C}$ for 01 minute and $72^{\circ} \mathrm{C}$ for 10 minutes for the last cycle. Final PCR product was loaded in 1.5\% agarose gels with BenchTop 100 bp DNA Ladder (consists of 11 doublestranded DNA fragments with sizes from 100-1500 bp, Promega, Madison, WI USA) and ran at 80 Volt for 25 minutes.

\subsection{Ethical approval}

The protocol was approved by the Animal Welfare and Experimentation Ethics Committee of the Bangladesh Agricultural University and approval no: AWEEC/BAU/2019(44).

\section{Results}

\subsection{Isolation and preliminary identification of probiotic bacteria 3.1.1. Lactobacillus and Lactobacillus acidophilus}

On this study we observed that colonies on Lactobacillus MRS $\operatorname{Agar}^{\mathrm{TM}}$ (Himedia, India) were distinct white or whitish yellow, smooth round looking form. Gram's staining properties included positive, rod or ovoid shaped with tapering end. Lactobacillous species which was primarily confirmed as Lactobacillus acidophilus though performed negative result reaction in case of $10 \%$ carbohydrate (sugar) fermentation of D-Galactose, DSorbitol, Melebiose, Melizitose and MR, Indole, Oxidase, Citrate test but showed positive reaction in case of DFructose, L-Arabinose, Maltose, L-Rhamnose, D-Mannitol, D-Sorbitol, Methyl-alpha-D-Gluco-pyranosid, Amygdaline, D-Ribose, Lactose, Raffinose, Sucrose, Xylose, Trehalose, Arginine, Salicine, NAG amine and VP test (Tables 1 and 2). Carbohydrate fermentation tests were performed with the basal medium phenol red broth (ADSA, Barcelona, Spain). 


\subsubsection{Bacillus and Bacillus subtilis}

The surface was finely granular and slightly sticky, large, sporulated, rod-shaped bacteria (Merchant and Packer, 1967). Maximum of all these species as ellipsoidal, sub terminal endospore formed motile and on Bacillus Differentiation agar (Himedia, India) we found large ellipsoidal, slightly sticky, blue pure colonies. On this research study, primarily suspected Bacillus subtilis species performed negative reaction in case of D-Galactose, D-Fructose, L-Rhamnose, Arginine, NAG amine, Melizitose 10\% carbohydrate (sugar) fermentation and MR, Indole, Catalase, Oxidase, but showed positive results in $10 \%$ sugar solution of L-Arabinose, Maltose, DMannitol, D-Sorbitol, Amygdaline, Dextrose, D-Ribose, Melebiose, Sucrose, Lactose, Xylose, Dextrose, Raffinose, Trehalose, Salicine fermentation and VP, Citrate, ONPG, Gram's staining (Tables 1 and 2).

\subsubsection{Streptococcus and Streptococcus thermophilus}

In Nutrient Agar medium, normally produced small grayish round colonies. In Streptococcus Thermophilus Isolation Agar Medium $^{\mathrm{TM}}$, the colonies were round, flat, large grayish sticky in our study. On Blood Agar, it was non-haemolytic responded. Primarily suspected Streptococcus thermophilus species performed negative reaction in case of Maltose, L-Rhamnose, D-Mannitol, Amygdaline, Arginine, NAG amine, 10\% carbohydrate (sugar) fermentation and MR, VP, Indole, Oxidase, Citrate utilization, but showed positive results in 10\% sugar solution of D-Galactose, D-Fructose, L-Arabinose, D-Sorbitol, Dextrose, D-Ribose, Melebiose, Sucrose, Melizi tose, Xylose, Trehalose, Salicine, Raffinose fermentation, Catalase reaction and Gram staining (Tables 1 and 2). Gram's staining properties also included the cocci, non sporeforming, chain formed, but also in pair or single form microorganisms.

\subsubsection{Enterococcus and Enterococcus faecium}

On Enterococcus Faecium agar base (Himedia, India) we found luxuriant green colored pure colonies. On this research study, primarily suspected Enterococcus faecium species D-Galactose, D-Fructose, L-Arabinose, Amygdaline, Dextrose, D-Ribose, Sucrose, Melizitose, Arginine, Trehalose, Salicine, Raffinose showed positive results in 10\% carbohydrate (sugar) fermentation, Oxidase reaction and Gram's staining but performed negative result in 10\% sugar fermentation of Maltose, L-Rhamnose, D-Mannitol, D-Sorbitol and MR, VP, Indole, Catalase, Citrate, ONPG (Tables 1 and 2). Biochemical tests, such as sugar fermentation, coagulase, catalase, MR, VP, and indole tests, were performed as per the standard methods of Cheesbrough (1985).

\subsubsection{Bifidobacterium and Bifidobacterium bifidum}

On used BSM broth and then referred to selective TOS-Propionate Agar acc ${ }^{\mathrm{TM}}$ Medium acc. (Sigma-Aldrich, St. Louis, USA), the colonies were convex, creamy, white or grayish, glossy, smooth, neat-edgeed, soft, sticky. On Lactobacillus MRS Agar ${ }^{\mathrm{TM}}$ (Himedia, India), the colonies were dew drop like small flat, distinct brown colored. The findings in this study, primarily suspected as Bifidobacterium bifidum fermented D-Galactose, D-Fructose, Amygdaline, D-Ribose, Sucrose, NAG amine, Melebiose but did not ferment L-Arabinose, Maltose, LRhamnose, D-Mannitol, D-Sorbitol, Dextrose, Arginine, Melizitose, Xylose, Trehalose, Salicine, Raffinose. We pointed out that MR, VP, Catalase, Citrate reaction, Gram staining performed positive but Oxidase and Indole reactions were negative (Tables 1 and 2).

\subsection{Molecular detection of probiotic bacteria}

We found 186 Lactobacillus genus isolates, 102 Bacillus genus isolates, 112 Streptococcus genus isolates, 220 Enterococcus genus isolates and 33 Bifidobacterium genus on the basis of biochemical properties like 10\% solution of total 22 different sugars. Other biochemical tests like MR-VP, Oxidase, Catalase, Citrate utilization, MIU and Indole test were major. Genus was detected through specific genus target gene and 16S r DNA based PCR. Selected probiotic bacteria species were detected though species specific target gene PCR. We confirmed $23 \mathrm{~L}$. acidophilus species isolates, $14 \mathrm{~B}$. subtilis isolates, $19 \mathrm{~S}$. thermophilus isolates, 31 E. faecium isolates and 09 B. bifidum isolates at species level.

\subsubsection{Lactobacillus and Lactobacillus acidophilus}

Target 472 bp 16S rRNA gene fragment from all suspected Lactobacillus isolates were amplified by PCR, using the primers 16S rRNA (Figure 1a). Lactobacillus acidophilus isolates with species specific primers according to Song et al., 2000. A 210 bp target 16S-23S rDNA ISR gene was used to confirm L. acidophilus species (Figure $1 b)$. 
Table 1. Results of biochemical tests.

\begin{tabular}{|c|c|c|c|c|}
\hline Lactobacillus spp. & Bacillus spp. & Streptococcus spp. & Bifidobacterium spp. & Enterococcus spp. \\
\hline D-Galactose $(-v e)=186 / 750$ & D-Galactose $(-\mathrm{ve})=102 / 750$ & D-Galactose $(+v e)=112 / 750$ & D-Galactose $(+v e)=33 / 750$ & D-Galactose $(+v e)=220 / 750$ \\
\hline D-Fructose $(+v e)=186 / 750$ & D-Fructose $(-v e)=102 / 750$ & D-Fructose $(+v e)=112 / 750$ & D-Fructose $(+v e)=33 / 750$ & D-Fructose $(+\mathrm{ve})=220 / 750$ \\
\hline L-Arabinose $(+\mathrm{ve})=186 / 750$ & L-Arabinose $(+v e)=102 / 750$ & L-Arabinose $(+v e)=112 / 750$ & L-Arabinose $(-\mathrm{ve})=33 / 750$ & L-Arabinose $(+v e)=220 / 750$ \\
\hline Maltose $(+v e)=186 / 750$ & Maltose $(+\mathrm{ve})=102 / 750$ & Maltose $(-v e)=112 / 750$ & Maltose $(-v e)=33 / 750$ & Maltose $(-v e)=220 / 750$ \\
\hline L-Rhamnose $(+v e)=186 / 750$ & L-Rhamnose $(-v e)=102 / 750$ & L-Rhamnose $(-\mathrm{ve})=112 / 750$ & L-Rhamnose $(-v e)=33 / 750$ & L-Rhamnose $(-\mathrm{ve})=220 / 750$ \\
\hline D-Mannitol $(+\mathrm{ve})=186 / 750$ & D-Mannitol $(+\mathrm{ve})=102 / 750$ & D-Mannitol (-ve) $=112 / 750$ & D-Mannitol(-ve) = 33/750 & D-Mannitol (-ve) $=220 / 750$ \\
\hline D-Sorbitol $(-v e)=186 / 750$ & D-Sorbitol $(+v e)=102 / 750$ & D-Sorbitol $(+\mathrm{ve})=112 / 750$ & D-Sorbitol (-ve) $=33 / 750$ & D-Sorbitol $(-v e)=220 / 750$ \\
\hline $\begin{array}{l}\text { Methyl-alpha-D-Gluco } \\
\text { pyranoside }(+v e)=186 / 750\end{array}$ & Amygdaline $(+\mathrm{ve})=102 / 750$ & Amygdaline $(-\mathrm{ve})=112 / 750$ & gdaline & $220 / 750$ \\
\hline Amygdaline $(+\mathrm{ve})=186 / 750$ & Dextrose $(+v e)=102 / 750$ & Dextrose $(+\mathrm{ve})=112 / 750$ & Dextrose $(-v e)=33 / 750$ & Dextrose $(+\mathrm{ve})=220 / 750$ \\
\hline D-Ribose $(+v e)=186 / 750$ & D-Ribose $(+v e)=102 / 750$ & D-Ribose $(+v e)=112 / 750$ & D-Ribose $(+v e)=33 / 750$ & D-Ribose $(+v e)=220 / 750$ \\
\hline Melebiose $(-\mathrm{ve})=186 / 750$ & Melebiose $(+\mathrm{ve})=102 / 750$ & Melebiose $(+\mathrm{ve})=112 / 750$ & Melebiose $(+\mathrm{ve})=33 / 750$ & Melebiose $(+\mathrm{ve})=220 / 750$ \\
\hline Lactose $\quad(+\mathrm{ve})=186 / 750$ & Arginine $(-v e)=102 / 750$ & Arginine $(-\mathrm{ve})=112 / 750$ & Arginine $(-v e)=33 / 750$ & Xylose $(+\mathrm{ve})=220 / 750$ \\
\hline Raffinose $(+v e)=186 / 750$ & NAG amine $(-\mathrm{ve})=102 / 750$ & NAG amine $(-\mathrm{ve})=112 / 750$ & NAG amine $(+v e)=33 / 750$ & NAG amine $(+v e)=220 / 750$ \\
\hline Sucrose $(+v e)=186 / 750$ & Sucrose $(+v e)=102 / 750$ & Sucrose $(+\mathrm{ve})=112 / 750$ & Sucrose $(+v e)=33 / 750$ & Sucrose $(+v e)=220 / 750$ \\
\hline Melizitose $(-\mathrm{ve})=186 / 750$ & Melizitose $(-v e)=186 / 750$ & Melizitose $(+\mathrm{ve})=112 / 750$ & Melizitose (-ve) $=33 / 750$ & Melizitose $(+v e)=220 / 750$ \\
\hline $\begin{array}{lll}\text { Xylose, } & \text { Trehalose, } & \text { Arginine, } \\
\text { Salicine, NAG amine, } & \text { Raffinose } \\
(+\mathrm{ve})=186 / 750 & \end{array}$ & $\begin{array}{l}\text { Lactose, Xylose, Dextrose, Treha } \\
\text { lose, Salicine, Raffinose }(+\mathrm{ve})= \\
102 / 750\end{array}$ & $\begin{array}{l}\text { Xylose, } \quad \text { Trehalose, } \text { Salicine, } \\
\text { Raffinose }(+v e)=112 / 750\end{array}$ & $\begin{array}{l}\text { Xylose, Trehalose, Salicin, } \\
\text { Raffinose (-ve) }=33 / 750\end{array}$ & $\begin{array}{l}\text { Arginine, Trehalose, Salicine, } \\
\text { Raffinose }(+v e)=220 / 750\end{array}$ \\
\hline Primarilly, confirmed as & Primarilly, confirmed as & Primarilly, confirmed as & Primarilly, confirmed as & Primarilly, confirmed as \\
\hline Lacto bacillus acidophilus & Bacillus subtilis & Streptococcus thermophilus & Bifidobacterium bifidum & Enterococcus faecium \\
\hline
\end{tabular}


Table 2. Identification of selected probiotic bacterial species by biochemical properties.

\begin{tabular}{|c|c|c|c|c|c|c|c|}
\hline Name of Bacterial species & $\begin{array}{l}\text { Voges-Pros kauer } \\
\text { (VP) }\end{array}$ & $\begin{array}{l}\text { Methyl-Red } \\
\text { (MR) }\end{array}$ & Indole test & $\begin{array}{l}\text { Motility Indole Urea } \\
\text { (MIU) }\end{array}$ & $\begin{array}{l}\text { Citrate utilization } \\
\text { test }\end{array}$ & $\begin{array}{l}\text { Catalase } \\
\text { test }\end{array}$ & $\begin{array}{l}\text { Oxidase } \\
\text { test }\end{array}$ \\
\hline $\begin{array}{l}\text { Lactobacillus species (186/ } \\
750)\end{array}$ & + ve & $+\mathrm{ve}$ & - ve & -ve & -ve & - ve & - ve \\
\hline Bacillus species $(102 / 750)$ & -ve & +ve & - ve & + ve & $+\mathrm{ve}$ & +ve & +ve \\
\hline $\begin{array}{l}\text { Streptococcus species (112/ } \\
750)\end{array}$ & - ve & - ve & $-\mathrm{ve}$ & -ve & -ve & + ve & - ve \\
\hline $\begin{array}{l}\text { Bifidobacterium species } \\
(33 / 750)\end{array}$ & + ve & $+\mathrm{ve}$ & $-\mathrm{ve}$ & - -ve & $+\mathrm{ve}$ & + ve & - ve \\
\hline $\begin{array}{l}\text { Enterococcus species } \\
(220 / 750)\end{array}$ & - ve & -ve & - ve & -ve & - ve & - ve & +ve \\
\hline
\end{tabular}




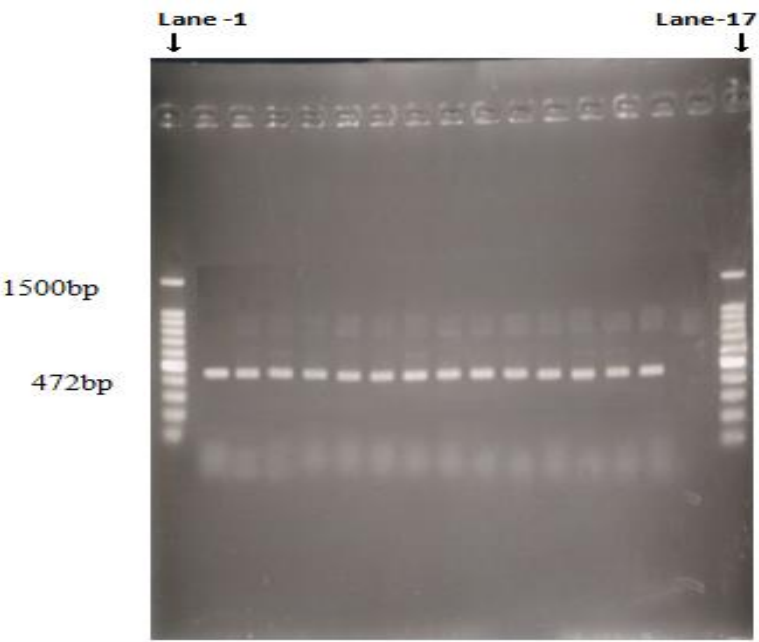

(a)

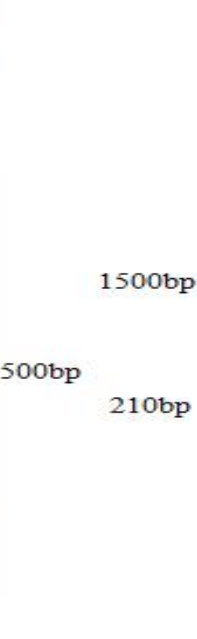

$10 \mathrm{bp}$

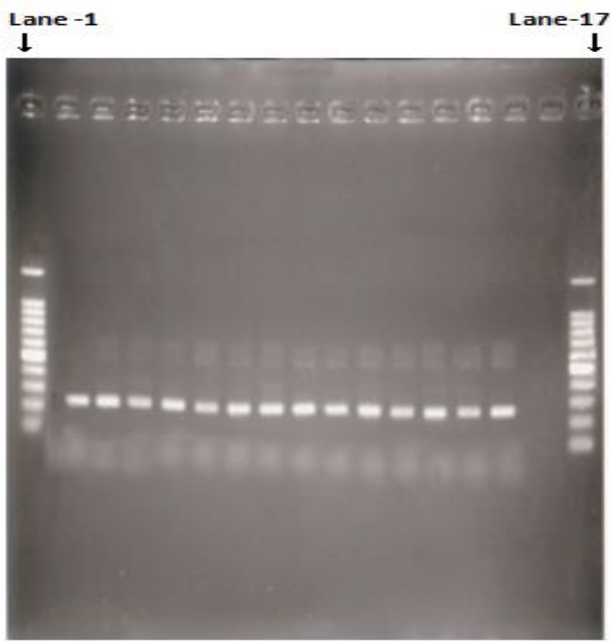

(b)

Figure 1. (a) Detection of Lactobacillus genus by 16S r RNA gene based PCR (Lane-1 \& 17=100bp Ladder DNA and Lane $2-15=$ positive samples \& Lane 16= Negative. (b) Detection of Lactobacillus acidophilus by $16 \mathrm{~S}-23 \mathrm{~S}$ ISR gene based PCR (Lane-1 \& 17=100bp Ladder DNA and Lane $2-15=$ positive samples \& Lane $16=$ Negative.

\subsubsection{Bacillus and Bacillus subtilis}

Target PCR band product size was $1.5 \mathrm{~kb}(1500 \mathrm{~kb})$ in where, 16S rRNA gene from all suspected Bacillus isolates were amplified by PCR using 27F forward and 1492R reverse primers sequence (Figure 2a). Target 744 bp apr-E genes with FW and REV primers sequence for B. subtilis (Figure $2 \mathrm{~b}$ ).

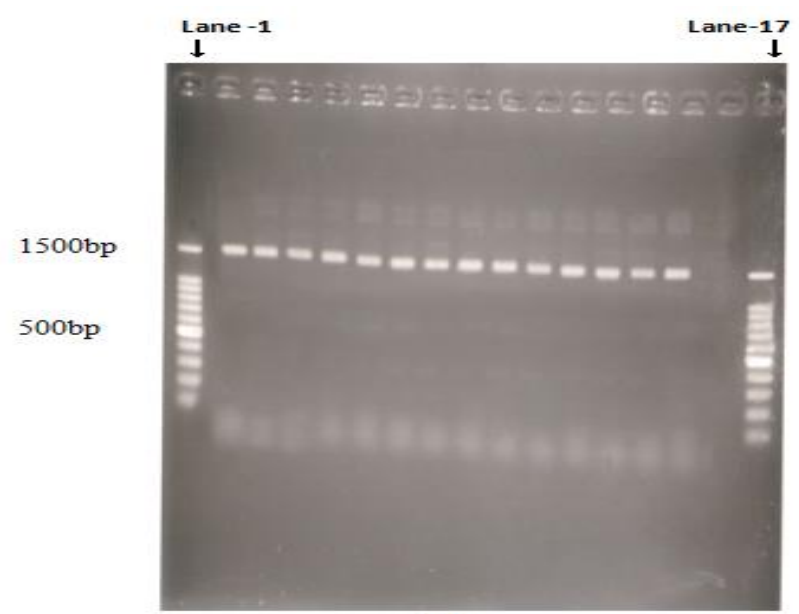

(a)

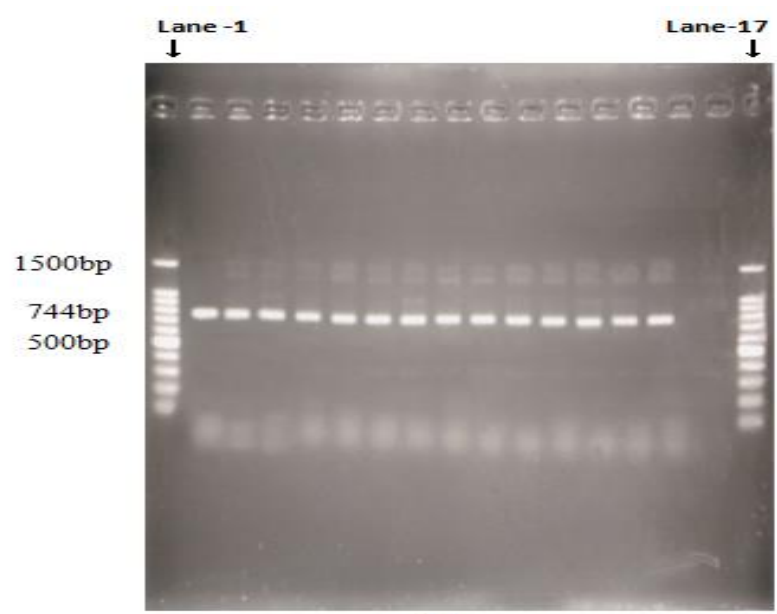

(b)

Figure 2. (a) Detection of Bacillus genus by $16 \mathrm{~S}$ r RNA gene based PCR (Lane-1 \& $17=100 b \mathrm{Ladder}$ Figure 2. (a) Detection of Bacillus genus by $16 \mathrm{~S}$ r RNA gene based PCR (Lane-1 \& $17=100 \mathrm{bp}$ Ladder
DNA and Lane $2-15=$ positive samples \& Lane $16=$ Negative. (b) Detection of Bacillus subtilis by apor$E$ gene based PCR (Lane-1 \& 17=100bp Ladder DNA and Lane 2- 15= positive samples \& Lane 16= Negative.

\subsubsection{Streptococcus and Streptococcus thermophilus}

The target amplicon size was 1505 bp with 8UA-FW and 1492-REV primers sequence (Figure 3a) by using primer pair specific to 16s rDNA of the genus Streptococci. All isolates of suspected S. thermophilus, a fragment 968 bp of Stp-TH-FW and Stp-TH-REV was detected confirming the correction assignation of the species to the genus Streptococcus (Figure 3b). 


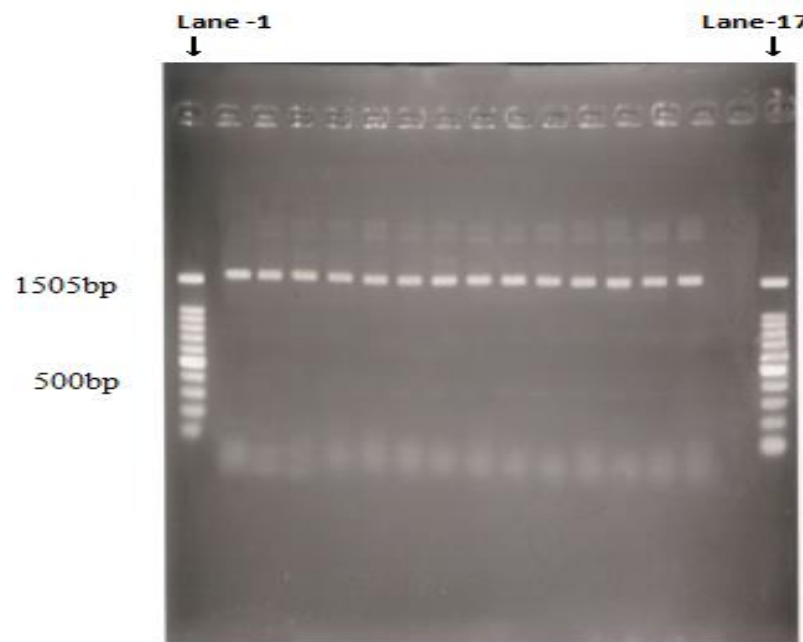

(a)

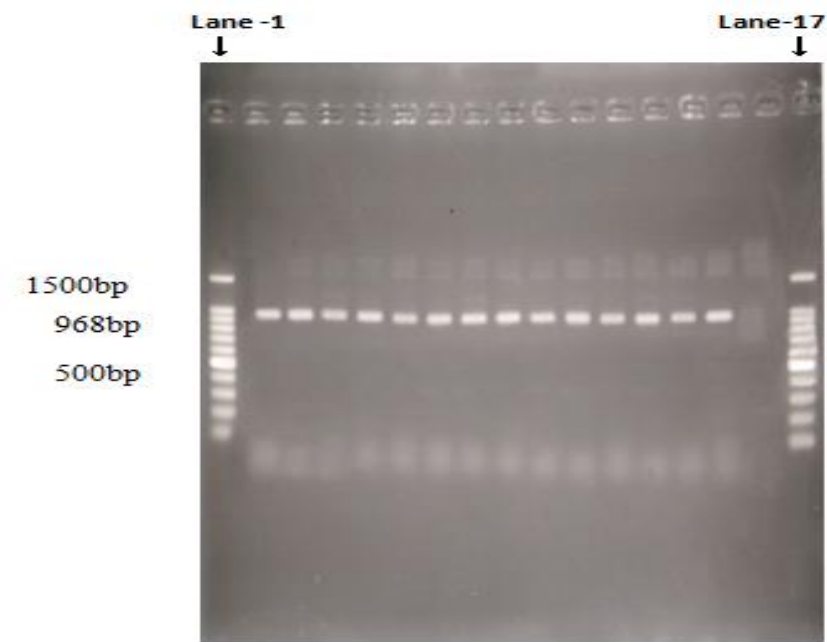

(b)

Figure 3. (a) Detection of Streptococcus genus by $16 \mathrm{~S}$ r RNA gene based PCR (Lane-1 \& $17=100 \mathrm{bp}$ Ladder DNA and Lane 2-15= positive samples \& Lane 16= Negative. (b) Detection of Streptococcus thermophilus by Stp-TH gene based PCR (Lane-1 \& 17=100bp Ladder DNA and Lane 2-15= positive samples\& Lane $16=$ Negative.

\subsubsection{Enterococcus and Enterococcus faecium}

The amplicon size of genus Enterococcus was 112 bp with Ent-1 FW, Ent-2 Rev primers targeting the 16S-23S $I S R$ rDNA (Figure 4a). Molecular detection of E. faecium from suspected isolates was performed targeting a 550 bp $d d l$ gene based species specific PCR (Figure 4b).

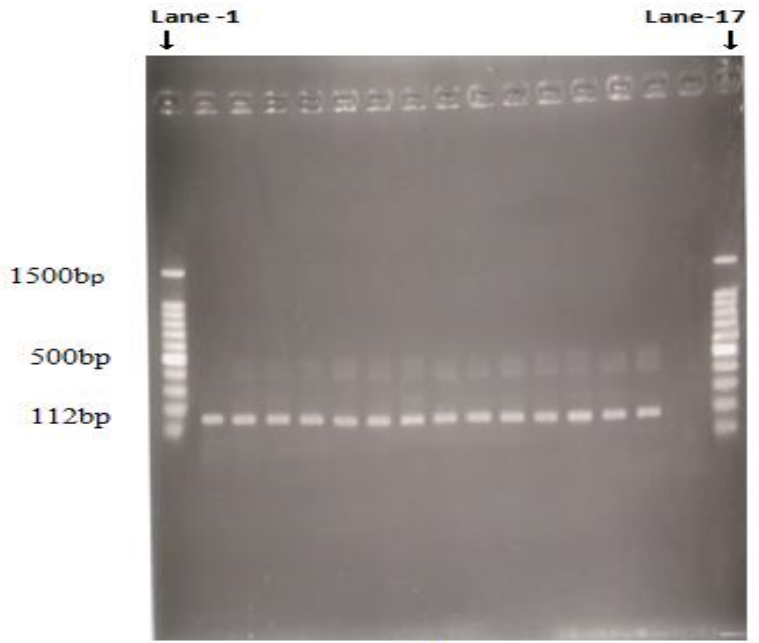

(a)

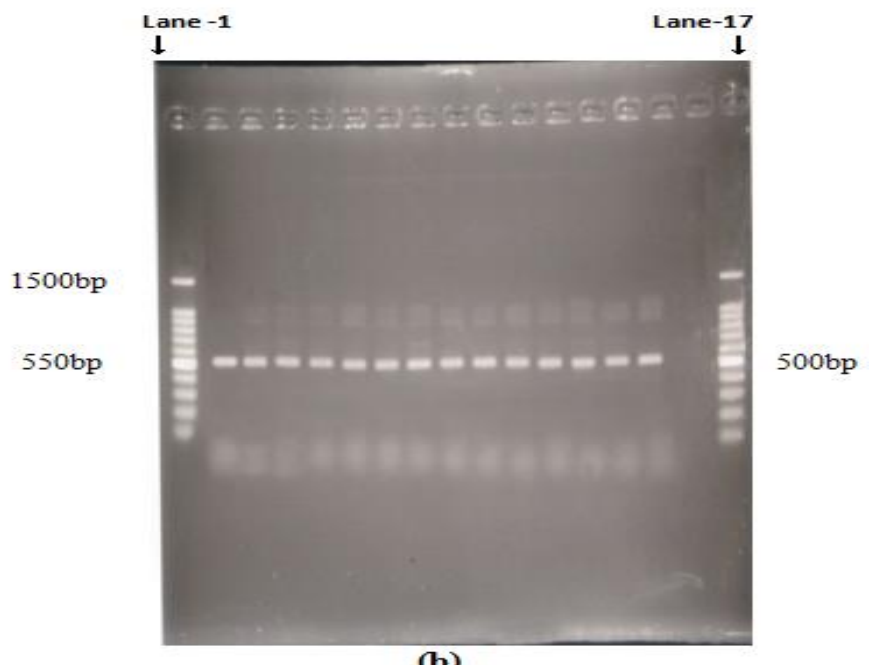

(b)

Figure 4. (a) Detection of Enterococcus genus by $16 \mathrm{~S}-23 \mathrm{~S} \mathrm{r}$ DNA ISR gene based PCR (Lane-1 \& $17=$ $100 \mathrm{bp}$ Ladder DNA and Lane 2 - 15= positive samples \& Lane 16= Negative. (b) Detection of Enterococcus faeciron by ddl gene based PCR (Lane-1 \& 17=100bp Ladder DNA and Lane 2 - $15=$ positive samples \& Lane $16=$ Negative.

\subsubsection{Bifidobacterium and Bifidobacterium bifidum}

In where, target PCR band product size was $510 \mathrm{bp}$ 16S rRNA gene from all suspected Bifidobacterium isolates and was amplified by using Bif164- forward and Bif662- reverse primers with sequence ( Figure 5a). We targeted a segment of 278 bp BIBI gene with FW and REV primers with sequence for detection of B. bifidum (Figure 5b). 


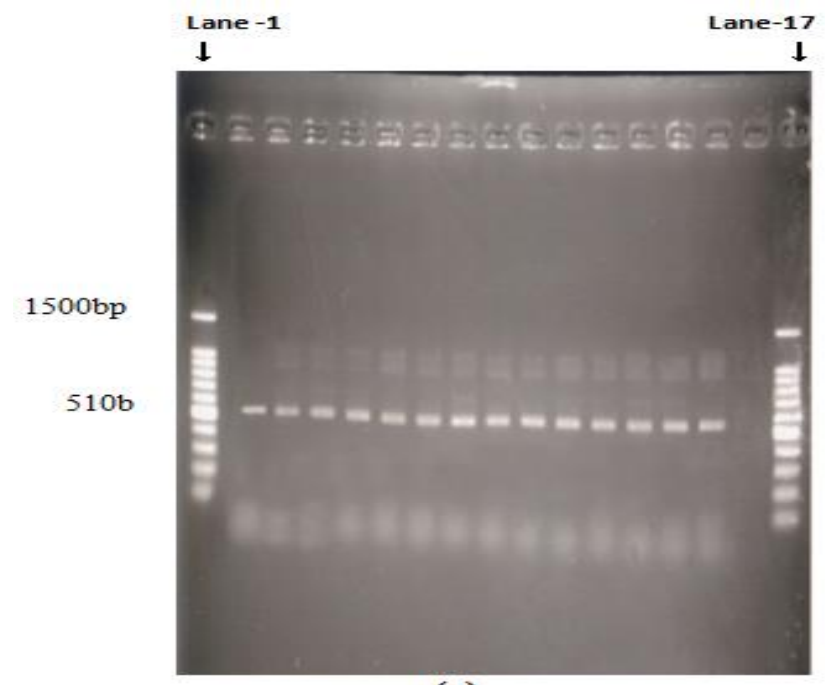

(a)

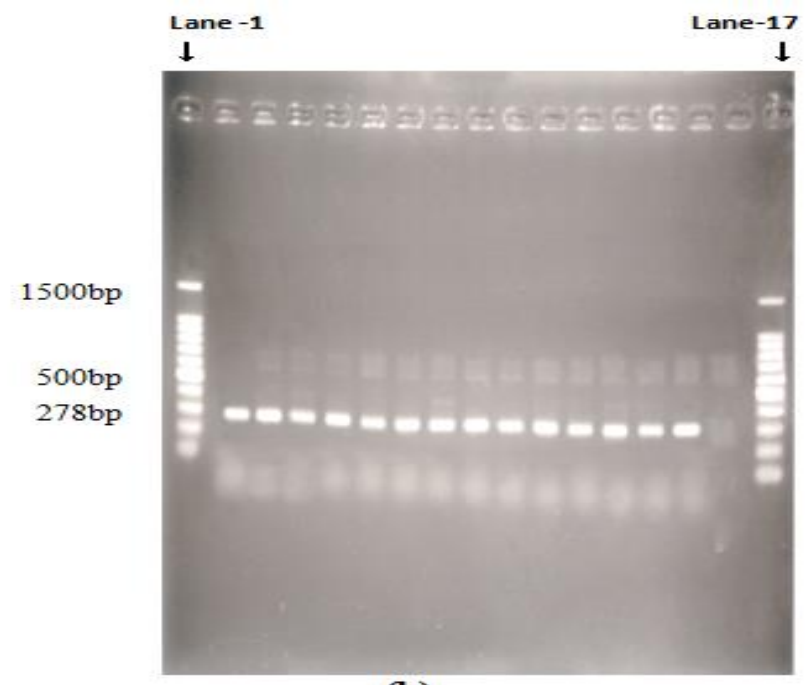

(b)

Figure 5. (a) Detection of Bifidobacterium genus by $16 \mathrm{~S}$ r RNA gene based PCR (Lane-1 \& $17=100$ bp Ladder DNA and Lane $2-15=$ positive samples \& Lane 16= Negative. (b) Detection of Bifidobacterium bifidum by $B I B I$ gene based PCR (Lane-1 \& $17=100$ bp Ladder DNA and Lane 2 $15=$ positive samples \& Lane $16=$ Negative.

\section{Discussion}

Carbohydrate tests produced a yellow color for a positive result and a red or red-orange color for a negative result agreeing to Albert and Anicet (1999). All these results were found relevant to the findings of Kamrun $e t$ al., 2016. On this study, we also observed that Lactobacillus species especially in case of MR, Indole, Oxidase, Citrate test Lactobacillus acidophilus species showed negative result. But positive reaction in case of VP test which is very similar to other research reports of many research workers on Lactobacillus acidophilus species. According to Parvaneh et al. (2016) D-Fructose, D-Galactose, L-Rhamnose, D-Mannitol, D-Sorbose, D-Ribose, Lactose, Raffinose, VP, Catalase showed negative result in case of $L$. acidophilus species which was not completely match with our study result. We had established our accuracy through PCR techniques at genus and species level which they did not do it, they only perform biochemical profiles. According to many researchers, this difference may due to variation in source of origin. Then all isolates were examined under bright field microscope to observe their microscopic features. These isolates were found gram positive, short and medium rod shaped, non-spore forming bacterium which indicates them to be member of Lactobacillus species (Thamaraj and Shah, 2003). The isolates were found catalase and oxidase negative and in IMViC (indole, methyl-red, voges proskauar, citrate utilization) tests all isolates were also found negative, thereby these might confirm the isolates were Lactobacillus species (Dhanasekaran et al., 2010). It differed from our study result. According to Narwade et al. (2015) Lactobacillus acidophilus species are non motile, indole test negative, methyl red test negative, voges proskauer positive, citrate negative, catalase negative, yellow colored colonies, size $<1 \mathrm{~mm}$, round shape, Gram's staining positive. Finally, our study results were compared with Bergey's manual of Bacteriology \& isolates were characterized as Lactobacillus species and specifically as L. acidophilus species. Some biochemical tests such as catalase test, oxidase test, indole test, Methyl Red (MR) test, Voges Proskauer (VP) test, citrate utilization test and carbohydrate fermentation patterns were performed as delineated by Bergey's manual systematic bacteriology to identify the Lactobacillus species (Hensyl, 1994). Biochemical tests, such as sugar fermentation, coagulase, catalase, MR, VP, and indole tests, were performed as per the standard methods (Cheesbrough, 1985). Gram's staining properties included the cylindrical rods, straight / slightly curved with rounded ends in case of long chain, presented in single or in chain. Spores are arranged in pair. Colony morphology on Nutrient Agar showed small, grayish and amoeboid with crenate margin and wool like edge. The surface was finely granular and somewhat dry with a ground glass appearance. The growth was membranous and slightly sticky. On Bacillus Medium ${ }^{\mathrm{TM}}$ and Bacillus Differentiation Agar ${ }^{\mathrm{TM}}$ (Himedia,India), Bacillus subtilis formed large, flat distinct, blue colonies. On later, from others biochemical tests and PCR technique, we were confirmed about those blue colored colonies which was Bacillus subtilis. Merchant and Packer (1967) reported that Bacillus species were Gram positive, cylindrical rods, straight or somewhat curved with rounded ends, present in singly or in chain. They stated that Bacillus species were on any nutrient agar medium was small, grayish with wool like edge. The surface was finely granular and slightly sticky, large, sporulated, rod-shaped bacteria which indicated very close to our observation. This study report is very similar 
to O'Donnell et al. (1980) though in case of Rhamnose, Galactose, N-Acetyl-Glucose-Amine, VP we observed negative result but he found variable. Granum (2001) reported that Bacillus species can ferment dextrose, maltose, lactose, sucrose and mannitol with production of acid. They are positive for Voges-Proskauer and methyl red test. On Nutrient Agar, colonies were thick, grayish-white or cream colored. Gram's staining showed positive, rod with square ends, large rod shaped organisms, arranged in chain and morphology and staining characteristics of $B$. subtilis recorded in this study are in agreement with the finding of Jones et al. (1987). According to Honda et al. (1982) all the isolates of B. subtilis fermented dextrose, sucrose, lactose, maltose but did not ferment mannitol with the production of acid within $24 \mathrm{~h}-48 \mathrm{~h}$ of incubation and reported positive reaction in VP test, negative reaction in MR and Indole test which are dissimilar to our study report. We also found maximum of all these species as ellipsoidal, sub terminal, endospore formed, motile and in case of other results not only MR, Catalase, Oxidase, Citrate, ONPG, VP, Indole but also maximum $10 \%$ carbohydrate sugar fermentation results are supported by Logan and Berkeley (1984) in where exceptions occurred in Fructose, Raffinose. Our study observation is also supported by Swetlana and Jain (2010). Bacterial identification was conducted based on morphological, physiological and biochemical tests and the results were compared with Bergey's Manual of Determinative Bacteriology, 8th edition (Buchanan and Gibbons, 1974) and The Genus Bacillus: Agriculture Handbook No. 427. The findings in this study were in accordance to the study of Devriese et al. (1987) where in L-Arabinose showed negative result and Raffinose, L-Rhamnose, Melizitose, Xylose showed variable positive and negative result though which is dissimilar to our study reports but the other results including these species as non-motile are same to our study reports. In Blood Agar, the colonies were small translucent with no haemolysis. In Hicrome ${ }^{\mathrm{TM}}$ Enterococcus Faecium Agar Base (Himedia, India), the colonies were luxuriant, distinct, green-colored in case of E. faecium. According to Alber and Anicet (1999) DGalactose, D-Fructose, Arginine, L-Arabinose, Amygdaline, Dextrose, D-Ribose, Melebiose, Xylose, NAG amine, Sucrose, Melizitose, Trehalose, Salicine, Raffinose and Oxidase reaction showed positive results in all of these sugar fermentation with a report of non-motile but performed negative results not only in case of Rhamnose, Sorbitol, Melizitose but also in case of MR,VP, Indole, Catalase, Citrate, ONPG reaction which are similar to our study results. But those of the fermentation results of Maltose, Raffinose are not same to our results. Rhamnose, Raffinose and Xylose fermentation results were variable (i.e, both positive and negative), reported by Schleifer et al. (1984) and Collins et al. (1986) which are not alike with our study results. Members of the genus Enterococcus include gram positive, facultatively anaerobic cocci that are ovoid in form and can occur in singlet, pairs or short chains (Facklam, 2002) which were accordance to our study results. Enterococcus species are homo fermentative lactic acid bacteria that lack cytochrome enzymes. In biochemical screens, Enterococcus species normally exhibit catalase-negative properties; yet some strains produce pseudocatalase and can appear to be weakly catalase positive (Murray, 1990). Other studies from many researchers pointed out that E. faecium from faecal samples and other sources exhibited similar results in biochemical reactions like acid production from arabinose, lactose, adonitol, sucrose and arginine dihydrolase and minor difference in the biochemical tests like mannitol, sorbitol and raffinose. According to Pelinescu et al. (2009), L-Arabinose, Starch, Glycogen showed positive result but Sorbitol and Raffinose showed negative result. Bridge and Sneath (1983) mentioned variable positive and negative result in case of Raffinose, D-Ribose, Melizitose, Maltose, Sorbitol, Mannitol, Galactose, Glycerol, Trehalose, Xylose, Arginine fermentation, VP but stated positive result in Lactose, Fructose, Starch fermentation, Catalase test and negative result in Rhamnose, Arabinose, Salicin, Amygdaline, NAG amine fermentation, MR, Indole, Oxidase, Motility Indole Urea test, Citrate test. In Blood Agar, Gamma haemolysis was variable responded in case of S. thermophilus. Holt et al. (1994) pointed out that Arabinose, Salicin, Maltose, Mannitol, Glycerol, Xylose fermentation were negative and Sucrose, Lactose showed positive result but not detected in Raffinose, Trehalose fermentation, VP reaction. Wasilewska et al. (2003) concluded that among 100 samples 90 samples found positive to Galactose, Lactose, Fructose, 50 samples found positive to Melibiose, Starch, Sucrose and every 10 samples found positive to Arabinose, Ribose, Maltose, Mannitol, Sorbitol, Salicine, Xylose, Lactose, Trehalose, Starch, Melizitose, Raffinose. They also concluded that though MR, VP, Catalase, Citrate reaction were positive but Indole, Oxidase reaction were negative. A conclusion from Iwana et al. (1993) prevailed that acid production by carbohydrate fermentation was detected by a change of the color of the phenol red indicator from red to yellow on the $4^{\text {th }}$ day and $10^{\text {th }}$ day of incubation. They also distinguished clearly that B. animalis and B. longum showed positive in case of Arabinose, xylose, Raffinose but $B$. bifidum showed negative result in our study. B. animalis and B. longum showed negative reaction in case of Ribose fermentation but we found it as a positive one. Fatima et al. (2013) marked that Maltose, Lactose, Galactose, Fructose, Melibiose, Sucrose, Salicine, Glucose fermentation, Citrate reaction was positive but Melizitose, Raffinose, Glycerol, Mannose, Rhamnose, Arabinose, Xylose, Trehalose, Ribose, Mannitol fermemtation, Catalase, Oxidase, Indole reaction were negative. They commented colony 
morphology as white, cream spatulate extremities, rod cell morphology. Gram's reaction was positive but non spore formed. In original description of Bifidobacteria, Tissier (1889) described curved rods and rods with ends split to give the characteristic "Y" shape which led to the designation of "bifid." In addition, bizarre small branches and bulbous or swollen ends were seen less frequently. Scardovi (1986) commented these bacteria are gram-positive pleomorphic, non-spore-forming, and non-motile, anaerobic bacteria with spatulate extremities (Cronin et al., 2011). Colonies are Gram positive, characterized by various forms, but often "bifid" forms (Scardovi, 1986) that are typical of Bifidobacteria. All the isolates were catalase and oxidase negative; these features have already been mentioned by several authors. Ewa et al. (2003) carried out studies proved that Bifidobacteria species differ significantly in morphology and biochemical activity. Among 750 our study samples, though we found 186 samples of Lactobacillus species positive through carbohydrate fermentation, biochemical properties, colony characteristics, cell morphology in distinguished media, Gram's staining and Polymerase Chain Reaction analysis but we confirmed about 23 samples that were L. acidophilus species with carbohydrate fermentation, biochemical properties and mostly trustworthy target gene based PCR. Identification of the Lactobacillus isolates with genus specific primers designed by Magne et al. (2006). As we have demonstrated here, amplification of the spacer regions by PCR can be carried out with suspensions of whole Lactobacillus cells, so colonies picked from agar plates can be used directly in identification of an isolate. For the majority of our Lactobacillus isolates, clear species identification could be made on the basis of percent similarity to GenBank sequences ( 97.5 to $100.0 \%$ similarity). The use of $16 \mathrm{~S}-23 \mathrm{~S}$ spacer sequences in the identification of Lactobacilli promises to be a valuable aid in advancing our knowledge of the species composition of Lactobacillus populations (Tannock et al., 1999). Kamrun et al. (2016) used a genus specific primer prepared by analyzing similarities between the nucleotide sequences of the spacer region between the 16 and 23S ribosomal RNA genes of Lactobacillus. The specificity of this genus specific primer combined with a universal primer was tested against 23 strains of Lactobacillus of varied origin. An expected sharp band of 200 bp amplicon was found for each sample which was corresponding to the 16-23S rRNA intergenic spacer region of Lactobacillus species. Thus all isolates were confirmed at genus level as Lactobacillus species. Amit et al. (2004) reported that Langendijk et al. (1995) also had supported the PCR-based techniques targeting the bacterial 16S rDNA to identify different bacterial species in fecal samples and others. However, the simultaneous use of universal primers directed at overall bacteria DNA had allowed them to extend this technique to estimate the relative proportions of different species present in the intestinal lumen of chickens. Recent advances in ribosomal DNA-based molecular techniques make it possible to identify different bacterial populations in environmental samples without cultivation. In this study, the intestinal microflora was examined using 16S ribosomal DNA (rDNA) targeted probes from bacterial DNA isolated from intestinal and cecal contents of chickens at 4, 14, and $25 \mathrm{~d}$ of age. Massi et al. (2004) used the primers 16-1A and 23-1B to amplify the ribosomal fragments comprising the internal transcribed spacers (ITS) and the flanking 16S and 23S rDNA regions of all Lactobacillus strains and in case of L. acidophilus the amplicon size was $199 \mathrm{bp}$. Chen et al. (2007) had commented that PCR amplification of the 16S-23S rRNA gene intergenic spacer region (IGSR) was found to be a useful tool for bacterial species-specific typing because of the considerable variability in size and sequence among organisms. Although combined biochemical and genetic analysis allowed the identification of the isolates to the genus level as Bacillus species, the API results and 16S rRNA sequences were not always in complete agreement (Teresa, 2005). Among 750 our study samples though we found 102 samples of Bacillus species positive through carbohydrate fermentation, biochemical properties, colony characteristics, cell morphology in distinguished media, Gram's staining and Polymerase Chain Reaction analysis but we confirmed about 14 samples that were Bacillus subtilis species with carbohydrate fermentation, biochemical properties and mostly credible target gene based PCR. We have followed detection of Bacillus isolates with genus specific primers described by Kim et al. (2010). This study finding is similar to Barbosa et al. (2005). However, some of the Bacillus strains almost share equal 16S rRNA gene sequences (99.2-99.6\%) which usually illustrate limited diversity for members of closely related strains (Nakamura et al., 1999). To overcome the above-mentioned obstacles, sequence analysis of housekeeping protein-coding genes and the multilocus sequence analysis (MLSA) have also been reported to be a helpful alternative in discriminating between closely related species (Kwon et al., 2009; Glazunova et al., 2009). Bacterial identification and distinction of these species using 16S rDNA sequencing also has major drawbacks. Analysis of $16 \mathrm{~S}$ rRNA gene sequences could not be used to distinguish B. subtilis and B. amyloliquefaciens because sequence similarities greater than $99 \%$ were found (Ash et al., 1991; Nakamura et al., 1999). Alternative phylogenetic markers have recently been described for differentiating closely related Bacillus species using protein-encoding genes housekeeping protein-coding genes like apr-E genes, rpoB, gyrA, gyrB, vrrA genes (Ki et al., 2009). Isolates of Bacillus subtilis detection at species level was carried out based on housekeeping protein-coding apr-E genes according to Alireza et al., 2012. Final 
PCR product was loaded in $1.5 \%$ agarose gels with BenchTop ${ }^{\mathrm{TM}} 100$ bp DNA Ladder (consists of 11 doublestranded DNA fragments with sizes from 100-1500 bp). These limitations for identification of species of Bacillus were discussed in detail previously (Van 2011) and the 16S rRNA genes sequences of species within the $B$. subtilis group were found to be too highly conserved to enable discrimination among species and subspecies (Shaver et al. 2002). This restriction prompted the search for and development of alternative conserved genetic markers having a greater degree of variability among strains compared with the 16S rRNA gene. The use of essential housekeeping genes that evolve more quickly than the 16S rDNA gene have proven to be useful for taxonomic classification (Palys et al., 2000). Sequence variations in the 16S rRNA genes may exist between some Bacillus strains within species and several Bacillus species were reclassified based on alignment of these sequences (Wu et al., 2006). However, the presence of highly conserved sequences in the 16S rRNA gene does not permit the discrimination among some species and subspecies of this group (Shaver $e t$ al. 2002). This observation was also true for the 10 reference strains of B. subtilis group in the present study that clustered together on 16S rRNA gene sequence analysis (Catia et al., 2008). We pointed out 220 samples of Enterococcus species positive among total 750 study samples, through carbohydrate fermentation, biochemical properties, colony characteristics, cell morphology in distinguished media, Gram's staining and Polymerase Chain Reaction analysis but we confirmed about 31 samples that were Enterococcus faecium species with carbohydrate fermentation, biochemical properties and mostly authorized target gene based PCR. The amplicon size of genus of Entericoccus was targeting the 16S-23S ISR rDNA according to Ke et al. (1999). Molecular detection of E. faecium from suspected isolates were performed according to Dukta-Malen et al. (1995) targeting $d d l$ gene species specific PCR. We used genus and species specific authenticated target gene from mostly précised previous works of many researchers for molecular detection. We also demarcated 112 samples of Streptococcus genus positive through carbohydrate fermentation, biochemical properties, colony characteristics, cell morphology in distinguished media, Gram's staining and Polymerase Chain Reaction analysis but we confirmed about 19 samples that were $S$. thermophilus species with carbohydrate fermentation, biochemical properties and mostly trustworthy target gene based PCR. Molecular detection of Streptococcus genus using PCR, primers pair specific to $16 \mathrm{~S}$ rDNA specific to Streptococcus was performed according to Sato et al. (2003). The target amplicon size which is similar to Rabeah et al. (2008). In where, the detection of the genus Streptococci was performed by using primer pair specific to 16s rDNA of the genus Streptococci. The positive amplified PCR product (1505 bp size), representing Streptococcus genus, was detected. All isolates of suspected Streptococcus thermophilus, species-specific primers Stp-TH-FW and Stp-TH-REV were selected for confirming the correction assignation of the species to the genus Streptococcus. Streptococcus thermophilus species were isolated from the all samples according to Jeanne et al. (2005). We delineated 33 samples of Bifidobacterium species positive through carbohydrate fermentation, biochemical properties, colony characteristics, cell morphology in distinguished media, Gram's staining and Polymerase Chain Reaction analysis but we resoluted about 09 samples that were B. bifidum species with carbohydrate fermentation, biochemical properties and mostly authenticated target gene based PCR. Bifidobacterium isolates with genus specific primers have described by Langendijk et al. (1995). In where, target gene from all suspected Bifidobacterium isolates were amplified by PCR using Bif164 forward and Bif662 reverse primers with sequence for Bifidobacterium genus identification. Delcenserie et al. (2005) reported that most of these molecular methods have been applied to detect Bifidobacterium species in human feces, rather than in the detection of Bifidobacteria of animal origin. Moreover, the 16S rRNA sequences are well conserved among the Bifidobacteria and there are multiple copies of the 16S rRNA gene per chromosome. The hsp60 gene, has been sequenced in most Bifidobacterium species (Jian and Dong, 2002). This gene presents species-specific sequences. Several molecular methods that alleviate this inconvenience have recently been described: PCR targeting the 16S rRNA (Bonjoch et al., 2004). Delcenserie et al. (2005) commented that four possibilities of results they observed (i) Only the target was positive (217 bp fragment), (ii) The target (217 bp) and the internal control (315 bp fragment) were positive. In these two cases, PCR was considered as positive for Bifidobacteria detection. Isolates of Bifidobacterium bifidum detection at species level was carried out according to Matsuki $e t$ al. (1998). Target segment of BIBI gene with FW and REV primers with sequence was detected and PCR product was loaded in 2\% agarose gels with BenchTop 100 bp DNA Ladder (consists of 11 double-stranded DNA fragments with sizes from 100-1500 bp, Promega, Madison, WI, USA) and ran at 80 Volt for 25 minutes.

\section{Conclusions}

We used reference strains to cross check out our studied five bacterial species on context of carbohydrate fermentation, biochemical properties, colony characteristics, cell morphology in distinguished media, Gram's staining and Polymerase Chain Reaction analysis. The significance of this study is at first time in Bangladesh, 
we isolated and identified five selected potential probiotic bacteria species which belongs to five genera at a repercussion, from the gastro-intestinal tract of broiler chickens and their environmental sources like litter, feeder and water drinker by linkage not only traditional cultural, biochemical techniques but also modern genus and species specific trustworthy target gene based molecular detection (PCR).

\section{Acknowledgments}

This study was performed in partial fulfillment for the requirements of a Ph.D. thesis of Tuhin-AL-Ferdous from the Department of Microbiology and Hygiene, Bangladesh Agricultural University, Mymensingh, Bangladesh. This study was supported by a project (Project No. 2015/271/MoE)) funded by the Ministry of Education, Government of the People's Republic of Bangladesh, Bangladesh Secretariat, Dhaka-1000, Bangladesh. We are thankful to Central Laboratory of Bangladesh Agricultural University, Mymensingh and University of Technology Sydney, Australia for their help during this research.

\section{Conflict of interest}

None to declare.

\section{References}

Albert M and RB Anicet, 2002. Identification of Enterococcus spp. based on specific hybridisation with $16 \mathrm{~S}$ rDNA probes. J. Microbial. Meth., 50: 115-121.

Alireza S, AM Seyed, RB Ahmad and S Balal, 2012. Design of multiplex PCR for simultaneous detection of rope-forming Bacillus strains in Iranian bread dough. J. Sci. Food. Agricul., 1: 22-27.

Amit RE, D Sklan and Z Uni, 2004. Microflora ecology of the chicken intestine using 16S ribosomal DNA primers. Poult. Sci., 83:1093-1098.

Barbosa TM, CR Serra, RM La Ragione, MJ Woodward and AO Henriques, 2005. Screening for Bacillus isolates in the broiler gastrointestinal tract. Appl. Environ. Microbiol., 71: 968-978.

Bonjoch X, E Balleste and AR Blanch, 2004. Multiplex PCR with 16S rRNA gene-targeted primers of Bifidobacterium spp. to identify sources of fecal pollution. Appl. Environ. Microbiol., 70: 3171-3175.

Bridge PD and PHA Sneath, 1983. Numerical taxonomy of Streptococcus. Microbiol., 129: 565-597.

Catia ACM, Orlando BM, Clementino MM, 2008. Species-level identification of Bacillus strains isolates from marine sediments by conventional biochemical, 16S rRNA gene sequencing and inter-tRNA gene sequence lengths analysis. Ant. V. Leeuwenh., 93: 297-304.

Cerritos R, P Vinuesa, LE Eguiarte, EL Herrera, PLD Alcaraz, GJLArvizu, G Olmedo, V Souza, E Ramirez and JL Siefert, 2008. Bacillus coahuilensis sp. nov., a moderately halophilic species from a desiccation lagoon in the Cuatro Cienegas Valley in Coahuila, Mexico. Int. J. Syst. Evol. Microbiol., 58: 919-923.

Cheesbrough M, 1985. Medical laboratory manual for tropical countries. English Language Book Society, London, England, pp. 400-480.

Chen Z, D Saxena, P Caufield, Y Ge, M Wang and Y Li, 2007. Development of species-specific primers for detection of Streptococcus mutans in mixed bacterial samples. FEMS Microbiol. Lett., 272: 154-162.

Collins MD, JA Farrow and D Jones, 1986. Enterococcus mundtii sp. nov. Int. J. Syst. Bacteriol., 36: 8-12.

Cristiano B, SV Bruno, CPD Juliano, M Anita, S Adebayo, D Kiran and JA Todd, 2019. Bacillus subtilis DSM 32315 supplementation attenuates the effects of Clostridium perfringens challenge on the growth performance and intestinal microbiota of broiler chickens. Microorgan, 7: 71.

Cronin M, M Ventura, GF Fitzgerald and D Van Sinderen, 2011. Progress in genomics, metabolism and biotechnology of Bifidobacteria. Int. J. Food Microbiol., 149: 4-18.

Delcenserie V, N Bechoux, B China, G Daube and F Gavini, 2005. A PCR method for detection of Bifidobacteria in raw milk and raw milk cheese: comparison with culture-based methods. J. microbial. Meth., 61: 55-67.

Devriese LA, A Van de Kerckhove, R Kilpper-Bälz and KH Schleifer, 1987. Characterization and identification of Enterococcus species isolated from the intestines of animals. Int. J. Syst. Evol. Microbiol., 37: 257-259.

Dhanasekaran D, S Saha, NThajuddin, M Rajalakshmi and A Panneerselvam, 2010. Probiotic effect of Lactobacillus isolates against bacterial pathogens in fresh water fish. J. Coast. Dev., 13:103-112.

Dutka-Malen S, S Evers and P Courvalin, 1995. Detection of glycopeptide resistance genotypes and identification to the species level of clinically relevant enterococci by PCR. J. Clin. Microbiol., 33: 24-27.

Ewa W and B Maria, 2003. Isolation and identification of Bifidobacteria from infant gut. Poul. J. Food Nutr. Sci., 53: 90-94. 
Facklam R, 2002. History, taxonomy, biochemical characteristics, and antibiotic susceptibility testing of Enterococci. In: The enterococci: pathogenesis, molecular biology, and antibiotic resistance. Edited by Gilmore, ASM Press, Washington, DC, USA, pp. 1-46.

FAO/WHO, 2002. Guidelines for the evaluation of probiotics in food. Joint FAO/WHO working group report on drafting guidelines for the evaluation of probiotics in food, London.

Fatima M, M Hadadji, B Guessas and M Kihal, 2013. Identification and physiological properties of Bifidobactérium strains isolated from different origin. J. Food Scien. Engin., 3: 196-206.

Freeman AG, KM Schweikart and LL Larcom, 1987. Effect of ultraviolet radiation on the Bacillus subtilis phages SPO2, SPP1 and $\varphi 29$ and their DNAs. Mut. Res., 184:187-196.

Fuller R, 1989. Probiotic in man and animals. J. Appl. Bacteriol., 66:131-139.

Gavini F, CAM Pourcher, DM Neut, CR Omond, C Oger and D Izard, 1991. Phenotypic differentiation of Bifidobacteria of human and animal origins. Int. J. Syst. Evol. Microbiol., 41: 548-557.

Gibson T, R Gordon and I Genus, 1974. Bacillus Cohn 1872, in (Bergey's manual of determinative bacteriology), edit. (RE Buchanan \& NE Gibbons), 8: 529-550.

Glazunova OO, D Raoult and V Roux, 2009. Partial sequence comparison of the rpoB, sodA, groEL and gyrB genes within the genus Streptococcus. Int. J. Syst. Evol. Microbiol., 59: 2317-2322.

Granum PE, 2001. Bacillus cereus. In: Food Microbiology: fundamentals and frontiers. Edited by Doyle MP, LR Beuchat and TJ Montville, American Society for Microbiology, Washington, DC, USA, pp. 327-336.

Hensyl WR, 1994. Bergey's Manual of Systematic Bacteriology. Williams and Wilkins, Baltimore, USA.

Holmes DE, KP Nevin and DRLovley, 2004. Comparison of 16S rRNA, nifD, recA, gyrB, rpoB and fusA genes within the family Geobacteraceae fam. nov. Int. J. Syst. Evol. Microbiol., 54:1591-1599.

Holt JG and NR Krieg, 1994. Bergey's Manual of Determinative Bacteriology. Williams \& Wilkins, Maryland, USA, pp. 538-558.

Honda T, M Arita, Y Takela and T Miwatani, 1982. Further evaluation of the Biken Test (Modified Eleck Test) for deletion of enterotoxigenic E. coli producing heat stable enterotoxin and application of the test to sampling of heat stable enterotoxin. J. Clin. Microbiol., 16:60-62.

Iwana $\mathrm{H}, \mathrm{H}$ Masuda, $\mathrm{T}$ Fujisawa, $\mathrm{H}$ Suzuki and $\mathrm{T}$ Mitsuoka, 1993. Isolation and identification of Bifidobacterium spp. in commercial yoghurt sold in Europe. Bifidobac. Microfl., 12: 39-45.

Jeanne D, B Bette, G Cheryl, A Martin, VS Raja and M Richard, 2005. Evaluation of five probiotic products for label claims by DNA extraction and polymerase chain reaction analysis. Dig. Dis Sci., 50: 1113-1117.

Jian W and X Dong, 2002. Transfer of Bifidobacterium inopinatum and Bifidobacterium denticolens to Scardovia inopinata gen. nov., comb. nov., and Parascardovia denticolensgen gen. nov., comb. nov., respectively. Int J Syst Evol Microbiol., 52: 809-812.

Jones D, 1978. Streptococci. In: Composition and differentiation of the genus Streptococcus. Edited by FA Skinner and LB Quesnel, Academic Press, London, pp. 1-49.

Jones TO, 1987. Intramammary antibiotic preparations and cephalosporin resistance in Salmonella typhimurium 204c. Vet. Rec., 120: 399-400.

Kabir SML, SMM Rahman, SB Neogi, MM Rahman and MSR Khan, 2016. Isolation, identification, molecular characterization and screening of probiotic activities of Lactobacillus species from poultry sources at live bird markets in Mymensingh, Bangladesh. Asian Australas. J. Biosci. Biotechnol., 1: 54-65.

Kabir SML, 2009. The role of probiotics in the poultry industry. Int. J. Mol. Sci., 10: 3531-3546.

Kamrun NI, A Touaha, A Fahmida and NI Nazneen, 2016. Characterization and confirmation of Lactobacillus spp. from selective regional yoghurts for probiotic and interference with pathogenic bacterial growth. Asian J. Biol. Sci., 9: 1-9.

Ke D, FJ Picard, F Martineau, CMénard, PH Roy, M Ouellette and MG Bergeron, 1999. Development of a PCR assay for rapid detection of enterococci. J. Clin. Microbiol., 37: 3497-3503.

Kim PI, JW Ryu, YH Kim and YT Chi, 2010. Production of biosurfactant lipopeptidesiturin A, fengycin, and surfactin A from Bacillus subtilis CMB32 for control of Colletotrichum gloeosporioides. J. Microbiol. Biotechnol., 20: 138-145.

Kwon GH, HA Lee, JY Park, JS Kim, J Lim, CS Park, DY Kwon, YS Kim and JH Kim, 2009. Development of a RAPD-PCR method for identification of Bacillus species isolated from Cheonggukjang. Int. J. Food Microbiol., 129: 282-287.

Langendijk PS, F Schut, GJ Jansen, GC Raangs, GR Kamphuis, MH Wilkinson and GW Welling, 1995. Quantitative fluorescence in situ hybridization of Bifidobacterium spp. with genus-specific 16S rRNAtargeted probes and its application in fecal samples. Appl. Environ. Microbiol., 61: 3069-3075.

Levine ND, 1975. Bergey's Manual of Determinative Bacteriology. Williams \& Wilkins Co., Baltimore, USA. 
Logan NA and RCW Berkeley, 1984. Identification of Bacillus strains using the API system. J. Gen. Microbiol., 130:1871-1882.

Magne F, M Abély, F Boyer, P Morville, P Pochart and A Suau, 2006. Low species diversity and high interindividual variability in faeces of preterm infants as revealed by sequences of 16S rRNA genes and PCR-temporal temperature gradient gel electrophoresis profiles. FEMS Microbiol. Ecol., 57: 128-138.

Massi MB, B Vitali, F Federici, D Matteuzzi and P Brigidi, 2004. Identification method based on PCR combined with automated ribotyping for tracking probiotic Lactobacillus strains colonizing the human gut and vagina. J. Appl. Microbiol., 96: 777-786.

Matsuki T, K Watanabe, R Tanaka and H Oyaizu, 1998. Rapid identification of human intestinal Bifidobacteria by 16S rRNA-targeted species-and group-specific primers. FEMS Microbiol. Lett., 167:113-121.

Merchant A and RA Packer, 1967. Veterinary bacteriology and virology. The Iowa University Press, Ames, Iowa, USA.

Murray BE, 1990.The life and times of the Enterococcus. Clin. Microbiol. Rev., 3: 46-65.

Nakamura LK, MS Roberts and FM Cohan, 1999. Relationship between the Bacillus subtilis clades associated with strains 168and W23: a proposal for B. subtilis subsp. subtilis and B. subtilis subsp. spizizenii. Int. J. Syst. Bacteriol., 49: 1211-1215.

Narwade RB, JD Kasare and RS Choudhary, 2015. Isolation, screening and characterization of Lactobacilli from cow milk. Int. J. Agric. Innov. Res., 3: 1635-1637.

O'donnell AG, JR Norris, RCW Berkeley, D Claus, T Kaneko, NA Logan and R Nozaki, 1980. Characterization of Bacillus subtilis, Bacillus pumilus, Bacillus licheniformis, and Bacillus amyloliquefaciens by pyrolysis gas-liquid chromatography, deoxyribonucleic acid-deoxyribonucleic acid hybridization, biochemical tests, and API systems. Int. J. Syst. Evol. Microbiol., 30: 448-459.

Palys T, E Berger, I Mitrica, LK Nakamura and FM Cohan, 2000. Protein-coding genes as molecular markers for ecologically distinct populations: the case of two Bacillus species. Int. J. Syst. Evol. Microbiol., 50: 10211028.

Parvaneh J, S Ahmadi, M Jamilian, EM Tajabadi and Z Asemi, 2016. The effects of synbiotic supplementation on markers of insulin metabolismand lipid profiles in gestational diabetes: a randomised, double-blind, placebo-controll edtrial. Brit. J. Nutri., 116: 1394-1401.

Peera $\mathrm{H}$ and $\mathrm{V}$ James, 2013. Effects of probiotics on gut microbiota: mechanisms of intestinal immunomodulation and neuromodulation. Therap. Adv. Gastroenterol., 6: 39-51.

Rabeah RY, HI Malkawi, A Hiyasat and MM Hammad, 2008. A fast and sensitive molecular detection of Streptococcus mutans and Actinomyces viscosus from dental plaques. Jordan Journal of Biological Sciences, 1: $135-139$.

Sato T, J Matsuyama, T Kumagai, G Mayanagi, M Yamaura, J Washio and N Takahashi, 2003. Nested PCR for detection of mutans streptococci in dental plaque. Lett. Appl. Microbiol., 37: 66-69.

Scardovi V, 1986. Genus Bifidobacterium. In: Bergey's Manual of Systematic Bacteriology. Edit. Williams and Wilkins, Baltimore, Maryland, USA, pp. 1418-1434.

Shaver YJ, ML Nagpal, R Rudner, LK Nakamura, KF Fox and A Fox, 2002. Restriction fragment length polymorphism of rRNA operons for discrimination and intergenic spacer sequences for cataloging of Bacillus subtilis sub-groups. J. Microbiol. Methods., 50: 215-223.

Song YL, N Kato, CX Liu, Y Matsumiya, H Kato and K Watanabe, 2000. Rapid identification of 11 human intestinal Lactobacillus species by multiplex PCR assays using group-and species-specific primers derived from the 16S-23S rRNA intergenic spacer region and its flanking $23 \mathrm{~S}$ rRNA. FEMS Microbiol. Lett., 187:167-173.

Swetlana N and PC Jain, 2010. Feather degradation by strains of Bacillus isolated from decomposing feathers. Braz. J. Microbiol., 41: 196-200.

Tannock GW, 1999. Probiotics. In: A Critical Review: Identification of lactobacilli and Bifidobacteria. Edit. Horizon Scientific Press, Norfolk, England, pp. 45-56.

Teresa MB, RS Claudia, MLR Roberto, JW Martin and OH Adriano, 2005. Screening for Bacillus isolates in the broiler gastrointestinal tract. Appl. Environ Microbial., 71: 968-978.

Tissier MH, 1889. La reaction chromophile d' Escherichelet le Bacterium coli. CR. Acad. Sci., 51: 943-945.

Wasilewska E and M Bielecka, 2003. Isolation and identification of Bifidobacteria from infant gut. Pol. J. Food Nutr. Sci., 12: 90-94.

Wu XY, MJ Walker, M Hornitzky and J Chin, 2006. Development of a group-specific PCR combined with ARDRA for the identification of Bacillus species of environmental significance. J. Microbiol. Methods., 64: 107-119. 